\title{
Shear Strength of Recycled Aggregate Concrete
}

\author{
Khaldoun N. Rahal and Yazzan Alrefaei
}

\begin{abstract}
Five longitudinally reinforced beams were loaded in a four-point testing setup to test their shear behavior. The beams were three meters long, and their cross section was 150 $\mathrm{mm}$ by $420 \mathrm{~mm}$. All five beams were similar except for the percentage of replacement of natural coarse aggregates (NCA) with recycled coarse aggregates (RCA), which was $0 \%, 20 \%$, $50 \%, 75 \%$ and $100 \%$. The target concrete strength was $35 \mathrm{MPa}$, and the ratio of longitudinal reinforcement was $0.8 \%$.

The results have shown that the replacement of NCA with RCA had a significant effect on the results. It caused a considerable reduction in the shear strength of the reinforced beams and in the modulus of elasticity of the concrete cylinders. In general, the most significant reduction in shear strength and increase in midspan deflections were observed in the beam with $20 \%$ replacement.
\end{abstract}

Keywords-Beams, recycled aggregates concrete, shear strength

\section{Introduction}

RCA are typically weaker than NCA because of the cement paste adhering to their surface and because of the uncertainties about their origin. As a result, the use of RCA can lead to a weaker concrete $[1,2]$.

The shear resistance of reinforced concrete (RC) beams relies considerably on aggregate interlock, especially in members not containing transverse reinforcement [3]. Since RCA are weaker than conventional aggregates, it is important to research the effect of use of RCA on the shear behavior of beams.

This paper presents the test results of five longitudinally reinforced beams tested in shear. The beams were cast using concrete made with five different percentages of replacements of NCA with RCA recycled aggregates: $0 \%, 20 \%, 50 \%, 75 \%$ and $100 \%$. The specimen with $0 \%$ replacement was a control beam.

Khaldoun N. Rahal

Department of Civil Engineering

Kuwait University, Kuwait

Yazzan Alrefaei

Department of Civil Engineering

Kuwait University, Kuwait

\section{Experimental Program}

\section{A. Test Setup}

Fig. 1 shows the test setup. The test region on the right hand side of the specimens did not contain any transverse reinforcement. The opposite side was reinforced with stirrups to ensure that failure takes place in the test region.

All specimens were $150 \mathrm{~mm}$ in width and $420 \mathrm{~mm}$ in depth, and contained three 14-mm bars tension bars and two 8$\mathrm{mm}$ bars as compression bars. The concrete clear cover to the longitudinal steel was $25 \mathrm{~mm}$, and consequently the effective depth $d$ to the center of the longitudinal bars was $388 \mathrm{~mm}$.

The ratio of the shear span to the effective depth was 3 . This ensures a "shallow beam" behavior, with a limited transfer of the load via arching effects.

\section{B. Concrete and Reinforcing Steel}

Five different mixes were used in the production of concrete whose target compressive strength was $35 \mathrm{MPa}$. Sieve analysis results were used to ensure that the gradation does not differ significantly when partial replacement is used. The coarse aggregates were brought to an SSD conditions before use. The sand was used in its storage conditions. The water added to the mix was modified to compensate for the actual moisture conditions of the air-dry sand used.

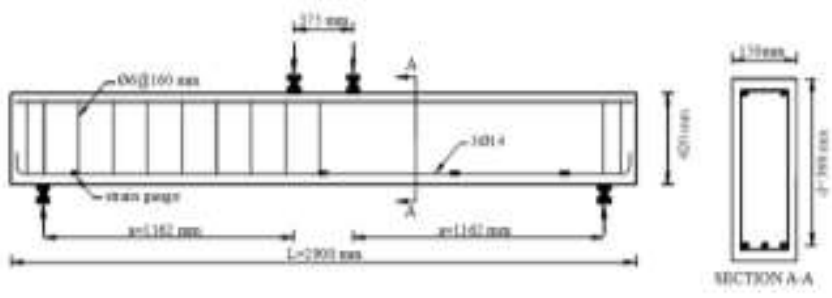

Fig. 1: Test setup

TABLE I. PROPERTIES OF CONCRETE

\begin{tabular}{|c|c|c|c|c|}
\hline Specimen & $\begin{array}{c}R C A \\
(\%)\end{array}$ & $\begin{array}{c}f_{c y} \\
(\mathrm{MPa})\end{array}$ & $\begin{array}{c}E_{c y} \\
(\mathrm{GPa})\end{array}$ & $\begin{array}{c}f_{c u} \\
(\mathrm{MPa})\end{array}$ \\
\hline $35-\mathrm{A}-0-00$ & 0 & 35.6 & 21.5 & 37.7 \\
\hline $35-\mathrm{A}-0-20$ & 20 & 33.4 & 21.1 & 35.0 \\
\hline $35-\mathrm{A}-0-50$ & 50 & 36.2 & 19.8 & 38.1 \\
\hline 35-A-0-75 & 75 & 35.7 & 21.5 & 36.6 \\
\hline 35-A-0-100 & 100 & 32.2 & 16.5 & 35.8 \\
\hline
\end{tabular}


Proc. of the Intl. Conf. on Advances in Civil, Structural and Mechanical Engineering - ACSM 2015.

Copyright $(\subseteq$ Institute of Research Engineers and Doctors, USA . All rights reserved.

ISBN: 978-1-63248-039-2 doi: 10.15224/ 978-1-63248-039-2-91

Standard cylinders and $150 \mathrm{~mm}$ cubes were cast from the same concrete of the beams. All concrete was covered with wet burlap and plastic sheets to maintain adequate moisture conditions. Moisture curing was continued for seven days. Then all concrete specimens were air cured in the lab until the day of the test.

Table 1 shows a summary of the results. The terms $f_{c y}, E_{c y}$ and $f_{c u}$ refer to the compressive strength of the cylinders, the modulus of elasticity, and the compressive strength of the 150 $\mathrm{mm}$ cubes, respectively.

Samples of the reinforcing steel were tested according to the relevant ASTM standards. The yield and ultimate strengths of the 14-mm bars used as tension reinforcement was $552 \mathrm{MPa}$ and $656 \mathrm{MPa}$, respectively. For the 8-mm bars used as compression reinforcement, these strengths were $308 \mathrm{MPa}$ and $371 \mathrm{MPa}$, respectively.

\section{Experimental Results}

Table 2 gives a summary of the ultimate loads $P_{u}$ of the five specimens. It also lists the ultimate shear forces $V_{u}$, estimated at $\mathrm{d} / 2$ away from the face of load by including a contribution of $1.2 \mathrm{kN}$ shear force from the self-weight of the beams.

All specimens failed in shear in the test region. Strain gauges attached to the longitudinal reinforcement at different locations along the length of the beam, including at midspan, confirmed that the strains remained well below yield levels.

TABLE II. SUMMARY OF RESULTS

\begin{tabular}{|c|c|c|c|c|c|}
\hline Specimen & $\begin{array}{c}R C A \\
(\%)\end{array}$ & $\begin{array}{c}P_{u} \\
(\mathrm{kN})\end{array}$ & $\begin{array}{c}V_{u} \\
(\mathrm{kN})\end{array}$ & $\frac{v_{u}}{\sqrt{f_{c y}}}$ & $R$ \\
\hline 35-A-0-00 & 0 & 109 & 55.7 & 0.160 & 1.0 \\
\hline $35-\mathrm{A}-0-20$ & 20 & 80.1 & 41.2 & 0.123 & 0.76 \\
\hline 35-A-0-50 & 50 & 93.9 & 48.2 & 0.138 & 0.86 \\
\hline 35-A-0-75 & 75 & 94.8 & 48.6 & 0.140 & 0.87 \\
\hline 35-A-0-100 & 100 & 85 & 43.7 & 0.132 & 0.825 \\
\hline
\end{tabular}

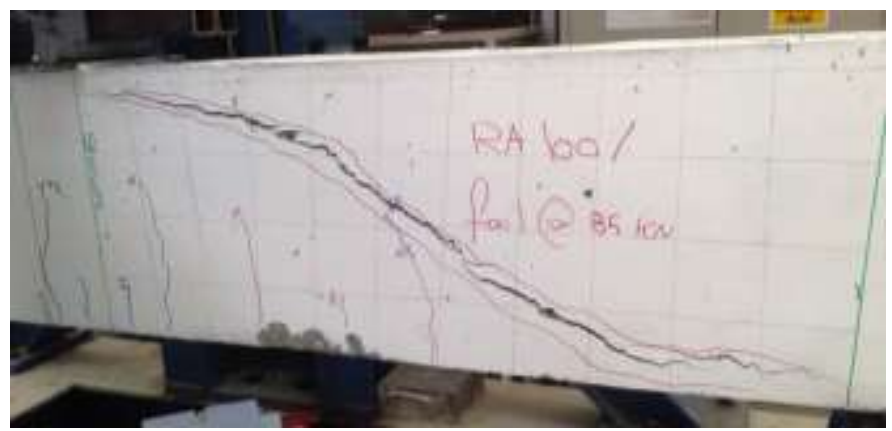

Fig. 2: Failure conditions of specimen 35-A-0-100

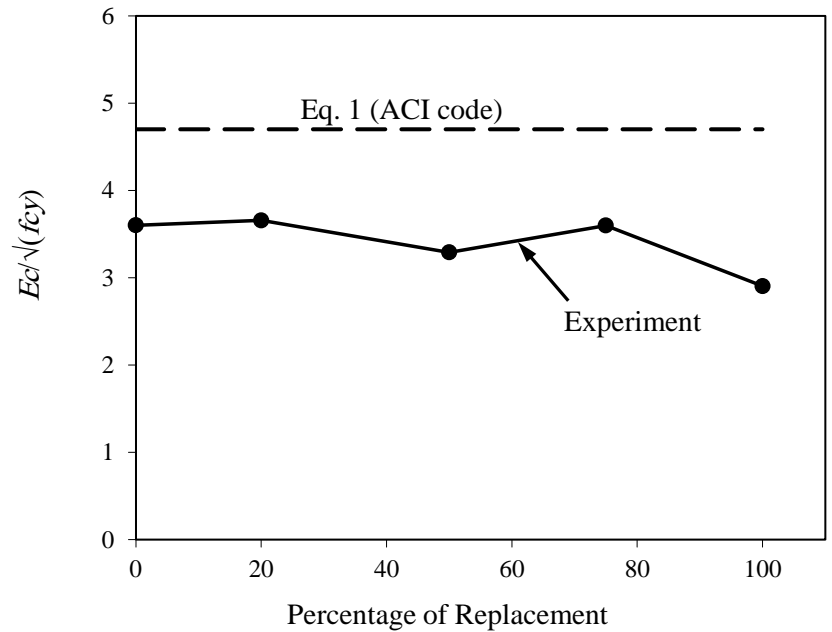

Fig. 3: Normalized modulus of elasticity

Figure 2 shows the conditions of the test region of 35-A-0100 after reaching the ultimate conditions. In general, the crack pattern before and at failure did not depend on the percentage of RCA.

\section{A. Modulus of Elasticity}

Fig. 3 shows the experimentally measured modulus of elasticity $E_{c}$ of the five concretes used versus the percentage of replacement. To minimize the effects of the slight difference in compressive strength, the modulus values are normalized with respect to the square root of the cylinder compressive strength. In general, the use of RCA decreased the modulus of elasticity of the concrete. The maximum reduction was about $19 \%$ for $100 \%$ replacement.

The ACI code [3] recommends the following equation for the calculation of normal-weight concrete:

$$
E_{c}=4700 \sqrt{f_{c y}}
$$

The results of Eq. (1) are plotted in Fig. 3. The comparison shows that for all the concrete used, the ACI equation over-estimated the modulus of elasticity.

\section{B. Ultimate Strength}

The results of the ultimate strength are normalized with respect to the square root of the cylinder compressive strength and are shown in Table II and Fig. 4. The table shows the ratio $R$ which is the ultimate shear strength of the beams normalized with respect to the strength of the control beam 35A-0-0. Fig. 4 and Table II show that the use or RCA reduced the shear strength of the concrete beams. The maximum reduction was about $17.5 \%$ and it was observed in the specimen with a replacement of $20 \%$. 
Proc. of the Intl. Conf. on Advances in Civil, Structural and Mechanical Engineering - ACSM 2015.

Copyright $(\odot$ Institute of Research Engineers and Doctors, USA . All rights reserved.

ISBN: 978-1-63248-039-2 doi: 10.15224/ 978-1-63248-039-2-91

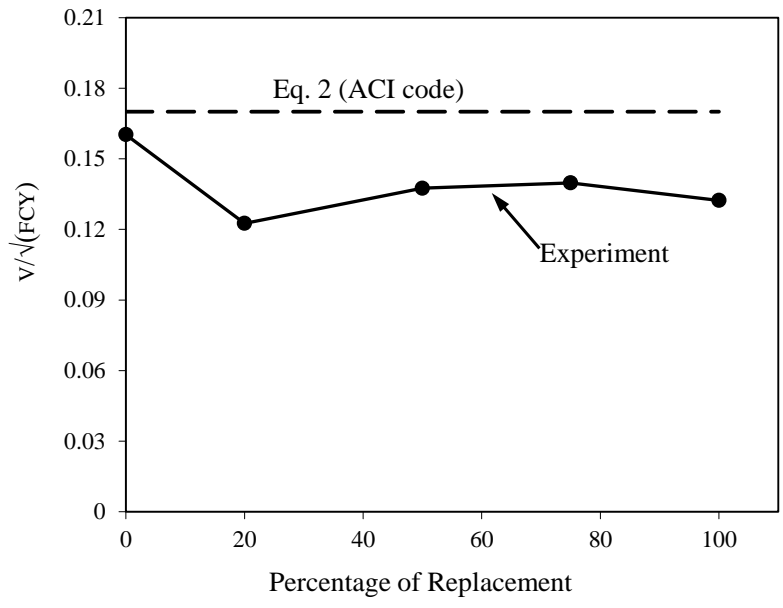

Fig. 4: Normalized ultimate shear strength

It is to be noted that previous research has reported cases where partial replacement of NCA with RCA was found to be more detrimental than full replacement. However, these observations were related to specimens with transverse reinforcement. Etxeberria et al. [4] reported that in beams with transverse steel, replacement with $50 \%$ and $100 \%$ RA did not have a significant effect on the ultimate shear strength but a $25 \%$ replacement caused a $13 \%$ decrease in this strength. In addition, Rahal and Al-Khaleefi [5] reported that a 50\% RCA replacement in pushoff specimens was more detrimental on the strength than a $100 \%$ replacement.

Fig. 4 also shows the ultimate strength calculated using the simplified equation of the ACI code [3] given by:

$$
v_{c}=0.17 \sqrt{f_{c y}}
$$

The figure shows that the equation of the ACI code was slightly unconservative for the control beam, and more unconservative for the recycled aggregate concrete specimens.

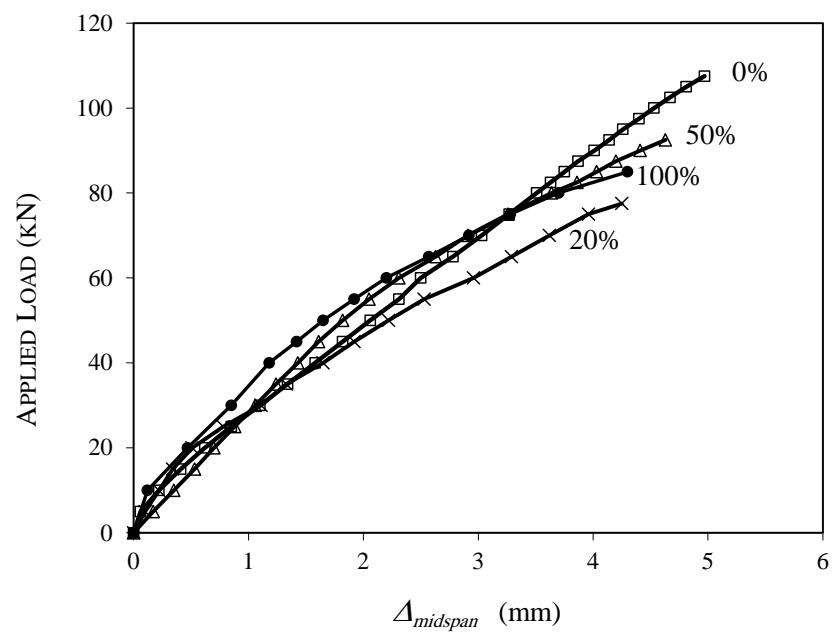

Fig. 5: Load versus deflection curves

\section{Load-Deflection Curves}

Fig. 5 shows the load versus midspan deflection curves for the five specimens. In general, the response was stiff because the longitudinal steel did not reach the yield strains. The control beam was stiffer than the remaining beams especially at higher load levels. The beam with $20 \%$ RCA replacement was not only the weakest, but also showed relatively larger deformations than the remaining specimens.

\section{Conclusions}

The shear behavior of five longitudinally reinforced specimens was tested using a four-point testing setup. The difference between the five specimens was the percentage of replacement of natural coarse aggregates with recycled coarse aggregates made of crushed waste concrete.

The experimental results showed the following

- The modulus of elasticity decreased as the percentage of coarse aggregates replacement increased. A maximum decrease of $19 \%$ was observed with a $100 \%$ replacement percentage. In all the concrete mixes, the equation of the ACI code over-estimated the modulus of elasticity.

- The ultimate shear strength decreased when natural aggregates were replaced with recycled aggregates. A maximum decrease of $17.5 \%$ was observed with a $20 \%$ replacement. The ACI equation over-estimated the shear strength of all the recycled aggregate concrete beams. It also slightly overestimated the ultimate strength of the control beam.

- The percentage of replacement affected the loaddeflection curves. In general, the specimen with a $20 \%$ RCA replacement showed relatively larger deflections than the remaining specimens

\section{Acknowledgment}

The research reported in this paper was supported by Research Sector, Kuwait University, Research Grant EV01/13. This support is gratefully acknowledged.

\section{References}

[1] K. Rahal, "Mechanical properties of concrete with recycled coarse aggregate,"," Building and Environment, vol. 42, pp. 407-415, 2007.

[2] M. S. De Juan and P. A. Gutierrez, "Study on the influence of attached mortar content on the properties of recycled concrete aggregate," Construction and Building Materials, vol. 23, no. 2, pp. 872-877, 2009.

[3] ACI Committee 318, "Building Code Requirements for Structural Concrete (ACI 318-11) and Commentary (318R-11)," American Concrete Institute, Farmington Hills, MI, 2011.

[4] M. Etxeberria, Mari, M. and E. Vazquez, "S Recycled aggregate concrete as structural material," Materials and Structures, vol. 40, pp. 529-541, 2007.

[5] K. Rahal and A. L. Alkhaleefi, "Shear-Friction Behavior of Recycled and Natural Aggregates Concrete - An experimental Investigation," Accepted for publication, ACI Structural Journal, 2015. 